\title{
Parâmetros biológicos de fêmeas adultas Amblyomma cajennense alimentadas em coelhos tratados com bioterápico ultradiluído
}

\author{
Biological parameters of Amblyomma cajennense adult females fed on rabbits \\ treated with ultradiluted biotherapic \\ Luciana Rodrigues de Almeida ${ }^{*}$ Nathalie Costa da Cunha ${ }^{\mathrm{I}}$ Raquel Silva Lisbôa $^{\mathrm{I}}$ \\ Renata Cunha Madureira' Charles Passos Rangel ${ }^{I}$ Eduardo Borges Viana ${ }^{\mathrm{I}}$ \\ Adivaldo Henrique da Fonseca ${ }^{\text {II }}$
}

\section{- NOTA -}

\section{RESUMO}

Os bioterápicos são considerados medicamentos homeopáticos por serem preparados de acordo com a farmacotécnica homeopática, submetidos à diluição e dinamização. Com o objetivo de avaliar os efeitos da administração de bioterápico ultradiluído sobre parâmetros biológicos de carrapatos Amblyomma cajennense, oito coelhos de três meses de idade, separados em dois grupos de quatro animais, constituindo os grupos tratado e controle, receberam o bioterápico na potência $30 \mathrm{DH}$ (Decimal Hering) e soro fisiológico $30 \mathrm{DH}$, respectivamente. Em seguida, os animais foram infestados experimentalmente com 10 casais de carrapatos A. cajennense e submetidos novamente aos referidos tratamentos. O bioterápico ultradiluído foi preparado a partir de carrapatos adultos machos e fêmeas de A. cajennense. Foram avaliados parâmetros biológicos relativos à postura $e$ à eclosão larval de A. cajennense. De acordo com os resultados obtidos, não foram detectados efeitos significativos sobre os parâmetros biológicos de fêmeas A. cajennense alimentadas em coelhos tratados com o bioterápico, quando comparados ao grupo controle. Novos testes, envolvendo outras espécies hospedeiras e o acompanhamento de infestações subseqüentes, devem ser dedicados à avaliação do potencial terapêutico profilático dos bioterápicos ultradiluídos nas ectoparasitoses dos animais domésticos.

Palavras-chave: Amblyomma cajennense, homeopatia, infestação experimental, coelho.

\section{ABSTRACT}

The biotherapics are considered homeopathic medicine because are produced in agreement to the homeopathic pharmacotechnic being diluted and dinamizated. To evaluate the effects of ultradiluted biotherapic on biologic parameters of Amblyomma cajennense ticks, 8 rabbits, about 3 months old, were divided into 2 groups of 4 animals each: treated and control groups which received biotherapic $30 \mathrm{DH}$ potency (Hering's decimal) and $30 \mathrm{DH}$ physiologic serum, respectively. Following, the animals were infested with 10 couples A. cajennense and treated again. The ultradiluted biotherapic was made with $\boldsymbol{A}$. cajennense male and female adult ticks. Significant alterations were not observed on biological parameters of females $\boldsymbol{A}$. cajennense fed on rabbits treated with the biotherapic, when compared to the control group. New tests, involving other host species and the attendance of subsequent infestations should be developed to evaluate the therapeutic / profilatic potential of the ultra-diluted biotherapics on infestation of the domestic animals.

Key words: Amblyomma cajennense, homeopathy, experimental infestation, rabbit.

Os métodos empregados no controle de carrapatos abordam práticas direcionadas às populações presentes no ambiente e no hospedeiro, tais como práticas de controle biológico e ecológico, tratamento químico com acaricidas, entre outros. Numerosos estudos têm sido dedicados também a abordagens imunológicas no controle de carrapatos e de outros artrópodes (MADRUGA et al., 2001).

A resposta imune natural contra os artrópodes hematófagos é dirigida, essencialmente, contra os antígenos presentes na saliva, os quais são inoculados no hospedeiro durante o repasto alimentar, sendo esta resposta pouco eficiente, pois não determina danos consideráveis ao artrópode. (RIBEIRO et al., 1985). Na resistência induzida, a expressão da resposta imune ocorre sobre o estágio adulto do ixodídeo, (WILLADSEN, 1980), sendo o principal mecanismo de proteção decorrente da atuação de anticorpos específicos (MASSARD et al., 1999).

ICurso de Pós-graduação em Ciências Veterinárias (CPGCV), Departamento de Parasitologia Animal, Universidade Federal Rural do Rio de Janeiro (UFRRJ), BR 465, Km 7, 23890-000, Seropédica, RJ, Brasil. E-mail: rodrigues_lu@yahoo.fr. *Autor para Correspondência. "Departamento de Epidemiologia e Saúde Pública, Instituto de Veterinária, UFRRJ, Seropédica, RJ, Brasil. 
De acordo com BASTIDE (1994), a administração de antígenos ultradiluídos (bioterápicos) é capaz de determinar modulação da resposta imune quando, posteriormente, o organismo for exposto ao referido antígeno. Tais ultradiluições, conhecidas como ultra high dilution (UHD), se apresentam entre as bases da terapêutica homeopática. A partir de potências equivalentes a 24DH, aproximadamente, não há mais presença de moléculas da substância original, pois o número de Avogadro foi ultrapassado. Contudo, várias são as evidências de que tais diluições continuem a exercer efeitos biológicos em sistemas vivos (WYNN, 1998; JONAS \& DILNNER, 2000).

Os bioterápicos, anteriormente denominados de nosódios, são considerados medicamentos homeopáticos por serem preparados de acordo com a farmacotécnica homeopática, sofrendo diluição e dinamização. Entretanto, o método é chamado de Isoterapia ou Isopatia, visto que segue não a Lei dos Semelhantes (Homeopatia: do grego, homoios: semelhante e pathos: doença), mas a Lei dos Iguais. Na Isoterapia, é empregado o próprio agente etiológico, visando uma reação terapêutica.

Embora os bioterápicos sejam amplamente empregados pela terapêutica homeopática, ainda são poucas as informações disponíveis, as quais evidenciem, por meio de metodologia adequada, a ação dos mesmos. Além disso, existem, atualmente, no mercado, formulações ditas homeopáticas, indicadas para o controle de ectoparasitas, entretanto, sem avaliações criteriosas prévias de sua eficácia.

O presente trabalho teve como objetivo avaliar os parâmetros biológicos de fêmeas adultas de Amblyomma cajennense alimentadas em coelhos submetidos ao tratamento com bioterápico preparado a partir de carrapatos desta espécie. Foram utilizados oito coelhos, com três meses de idade, da raça Nova Zelândia, com média de peso igual a 2,30g. Os animais foram separados casualmente em dois grupos de quatro animais, tratado e controle, mantidos em gaiolas individuais e receberam ração e água ad libitum. Os grupos tratado e controle receberam, diariamente, o bioterápico na potência de $30 \mathrm{DH}$ e soro fisiológico $30 \mathrm{DH}$, respectivamente, na dose de cinco gotas por via oral, durante 20 dias, com intervalo de dez dias na metade deste período. Em seguida, os animais foram experimentalmente infestados e submetidos aos referidos tratamentos durante mais 15 dias, de acordo com o protocolo proposto por NASI et al. (1982). O bioterápico ultradiluído foi preparado a partir de 20 carrapatos adultos machos e fêmeas de $\boldsymbol{A}$. cajennense, na forma líquida, de acordo com a Farmacotécnica Homeopática Brasileira (MS, 1997), em farmácia especializada. Os animais foram infestados com dez casais de carrapatos A. cajennense, de acordo com a metodologia empregada por NEITZ (1971). Decorridos oito dias da infestação, os dispositivos foram abertos diariamente para recuperação das fêmeas ingurgitadas desprendidas naturalmente, as quais foram levadas ao laboratório (Laboratório de Doenças Parasitárias da UFRuralRJ) e acondicionadas em estufa tipo BOD. Foram avaliados parâmetros biológicos relativos à postura e ao processo de eclosão larval, assim como à eficiência reprodutiva das fêmeas. Antes e após a infestação, foram colhidas amostras de sangue para determinação da leucometria global e contagem diferencial de leucócitos.

Entre as 80 fêmeas alimentadas em coelhos dos grupos tratado e controle, foram recuperadas $78,8 \%$, após período parasitário que durou em média 10,7 dias para ambos os grupos. De acordo com os resultados obtidos, não houve diferença significativa em relação às médias dos parâmetros biológicos avaliados de fêmeas $\boldsymbol{A}$. cajennense alimentadas em coelhos que receberam bioterápico ultradiluído ou soro fisiológico dinamizado ( $\mathrm{P}>0,05)$ (Tabela 1$)$.

KEMP et al. (1986) avaliaram parâmetros biológicos de Rhipicephalus (Boophilus) microplus alimentados em bovinos vacinados com extratos preparados a partir fêmeas desta espécie e observaram efeito significativo da vacinação sobre aspectos biólogicos da espécie, ressaltando que a resposta imunológica modulada difere da resistência natural dos animais aos carrapatos. De acordo com BROWN et al. (1984), os níveis de resposta determinados pela infestação por carrapatos dependem, entre outros fatores, da exposição prévia aos mesmos. Dessa forma, ressalta-se a necessidade de infestações experimentais subseqüentes, para avaliar se a administração do bioterápico seria capaz de modular a resposta imune do hospedeiro, afetando parâmetros biológicos dos carrapatos. De acordo com os resultados obtidos a partir da contagem global de leucócitos (Tabela 2), não

Tabela 1 - Médias dos parâmetros biológicos de fêmeas Amblyomma cajennense adultas alimentadas em coelhos tratados com bioterápico e com soro fisiologico dinamizado (controle).

\begin{tabular}{llll}
\hline & Tratado & Controle & \\
& $(\mathrm{n}=31)$ & $(\mathrm{n}=32)$ & \\
\hline & & & Valor de $\mathrm{p}^{*}$ \\
Peso das teleógenas (mg) & 371,9 & 348,4 & $\mathrm{p}>0,05$ \\
Período pré-postura (dias) & 6,3 & 6,18 & $\mathrm{p}>0,05$ \\
Peso da postura (mg) & 185,4 & 160,4 & $\mathrm{p}>0,05$ \\
Período de incubação (dias) & 39,7 & 38,6 & $\mathrm{p}>0,05$ \\
Percentual de eclosão (\%) & 33,5 & 33,4 & $\mathrm{p}>0,05$ \\
Eficiência reprodutiva & 15,9 & 15,5 & $\mathrm{p}>0,05$ \\
\hline
\end{tabular}

$\mathrm{n}=$ numero de fêmas $A$. cajennense recuperadas nos coelhos de cada grupo de tratamento.

* Nivel de significância igual a 5\%. 
Tabela 2 - Contagem global de leucócitos* e relação heterófilo: linfócito antes e após infestação experimental de coelhos por A. cajennense. Animais tratados com bioterápico e com soro fiosiologico dinamizado (controle).

\begin{tabular}{|c|c|c|c|c|c|c|c|c|}
\hline & \multicolumn{4}{|c|}{ Tratado } & \multicolumn{4}{|c|}{ Controle } \\
\hline \multicolumn{9}{|l|}{ Animais } \\
\hline & 1 & 2 & 3 & 4 & 5 & 6 & 7 & 8 \\
\hline 40 dias antes da infestação & $9800 / 0,47$ & $7400 / 0,89$ & $11100 / 0,92$ & $5700 / 1,40$ & $13200 / 1,43$ & $14200 / 1,51$ & $10000 / 1,02$ & $13700 / 0,78$ \\
\hline 3 dias antes da infestação & $9100 / 0,85$ & $7700 / 0,78$ & $12700 / 1,44$ & $8400 / 0,70$ & $10600 / 1,28$ & $11400 / 0,68$ & $11000 / 1,35$ & $12600 / 2,33$ \\
\hline 14 dias pós-infestação & $12300 / 1,21$ & $6100 / 1,45$ & $7800 / 1,55$ & $6300 / 0,95$ & $8400 / 1,74$ & $7900 / 1,42$ & $5900 / 0,68$ & $8300 / 0,86$ \\
\hline
\end{tabular}

*Leucócitos / $\mathrm{mm}^{3}$ de sangue.

foi detectada diferença significativa entre os parâmetros dos grupos tratado e controle $(\mathrm{P}>0,05)$. Foi observado que sete dos oito animais infestados apresentaram redução da leucometria global após a infestação, o que pode ser resultado da atividade imunossupressora característica da saliva dos artrópodes hematófagos (RIBEIRO et al., 1985).

Novos testes, envolvendo outras espécies hospedeiras e o acompanhamento de infestações subseqüentes, devem ser dedicados à avaliação do potencial terapêutico profilático dos bioterápicos ultradiluídos nas ectoparasitoses dos animais domésticos.

\section{REFERÊNCIAS}

BASTIDE, M. Immunological examples on ultra high dilution research. In: ENDLER ; SCHULTE (Eds). Ultra high dilution, physiology and physics. Dordrecht: Kluwer Academic, 1994. p.27-33.

BROWN, S.J. et al. Bovine resistance to Amblyomma americanum ticks: an acquired immune response characterized by cutaneous basophil infiltrates. Veterinary Parasitology, v.16, n.1-2, p.147-165, 1984.

JONAS, W.B.; DILNNER, D.K. Protection of mice from tularemia infection with ultra-low, serial agitated dilution prepared from Fransicella tularensis infected tissue. Journal of Scientific Exploration, v.14, n.1, p.35-52, 2000.

KEMP, D.H. et al. Immunization of cattle against Boophilus microplus using extracts derived from adult female ticks: feeding and survival of the parasite on vaccinated cattle. International Journal for Parasitology, v.16, n.2, p.115120, 1986 .

MADRUGA, C.R. et al. Imunodiagnóstico em medicina veterinária. Campo Grande: Embrapa Gado de Corte, 2001. 360p.

MASSARD, C.L. et al. Situação atual das vacinas contra carrapatos. In: SEMINÁRIO BRASILEIRO DE PARASITOLOGIA VETERINÁRIA, 11., 1999, Salvador, BA. Anais... Salvador: CBPV, 1999. p.40-42.

MINISTÉRIO DA SAÚDE. Farmacopéia homeopática brasileira. 2.ed. São Paulo: Atheneu, 1997.

NASI, A.M.T.T. et al. Emploi de biotherapiques dans le traitement de souris infectées par Trypanosoma cruzi resultats preliminaires. Annales Homeopathiques Françaises, v.24, n.3, p.53-64, 1982.

NEITZ, W.O. et al. Laboratory investigations on the lifecycle of the karoo paralysis tick (Ixodes rubicundus Neumann, 1904). Onderstepoort Journal of Veterinary Research, v.38, n.3, p.215-224, 1971.

RIBEIRO, J.M.C. et al. Antihaemostatic, antinflammatory and immunossupressive properties of the saliva of a tick, Ixodes dammini. Journal of Experimental Medicine, v.161, n.2, p.332-344, 1985.

WILladsen, P. Immunity to ticks. Advances in Parasitology, v.18, p.293-311, 1980.

WYNN, S.G. Studies on use of homeopathy in animals. Journal of the American Veterinary Medical Association, v.212, n.5, p.719, 724, 1998. 